\title{
Ecumenismo e o diálogo das religiões na perspectiva de Andrés Torres Queiruga
}

\author{
Ecumenism and dialogue of religions from the \\ perspective of Andrés Torres Queiruga
}

José Aguiar Nobre

\section{Resumo}

O tema do diálogo das religiões revela-se de grande complexidade, pois trata da tessitura do Mistério e suas implicações transcendentais. Reivindica dos interlocutores abertura e disponibilidade para romper preconceitos. Prevalece o convite para que todos permaneçam de mãos estendidas ao diálogo com ânimo para uma práxis renovadora. Essa abertura deve nascer do princípio de que todas as religiões são - a seu modo e em sua específica medida - verdadeiras. A partir da autocompreensão cristã e por meio do pensamento de Torres Queiruga, entendemos que existe uma radical e fraterna comunidade formada por todas as religiões, que devem buscar a máxima comunhão possível, como resposta ao amor universal de Deus. Compreendemos que o diálogo acontece na medida em que essa comunhão está presente nas confissões religiosas que se unem sem se imporem; aproximam-se sem se desrespeitarem, conservando cada uma a sua identidade, predisposta e receptiva, sempre em um clima de reforma.

Palavras-chave: Diálogo. Torres Queiruga. Religiões. Revelação divina.

\section{Abstract}

The dialogue of religions theme proves to be of great complexity as it speaks about the subject of the Mystery and its transcendental implications. 
It Claims the interlocutors openness and willingness to break prejudices. The invite for all to remain with their hands opened to dialogue prevails with enthusiasm for as refreshing praxis. This openness must be born from the principle that all religions are - in their own way and specific measure - true. From the Christian self-understanding and by the thought of Torres Queiruga, we acknowledge that there is a radical and fraternal community made up of all religions which should seek the maximum possible communion as a response to the universal love of God. We understand that the dialogue happens when this communion is present until the point where the religions confessions unite without imposing; get closer without disregarding, each one saving its identity, predisposed and receptive, always in a climate of reform.

Keywords: Dialogue. Torres Queiruga. Religions. Divine revelation.

\section{Introdução}

O tema do diálogo das religiões, por si só, revela-se de grande complexidade por se tratar da tessitura delicada do Mistério e suas implicações transcendentais. É um tema que reivindica dos seus seguidores uma abertura e disponibilidade a romper laços comuns e preconceitos. Em algumas posições, certamente a uns, as propostas parecer-lhes-ão ousadas e a outros, muito tímidas. Em todo caso, prevalece o convite para que todos permaneçam de mãos estendidas ao diálogo e que tenham ânimo para uma práxis renovadora. Essa abertura deve nascer do princípio de que "todas as religiões são - a seu modo e em sua específica medida - verdadeiras"1. A partir da autocompreensão cristã e por meio do pensamento de Torres Queiruga, entendemos que existe uma radical e fraterna comunidade formada por todas as religiões e, como resposta ao amor universal de Deus, sem eleições nem privilégios da parte d'Ele, todas devem buscar a máxima comunhão possível. "Só partilhando aquilo que crêem ser o melhor, num diálogo repleto de respeito e sempre disposto a dar e receber, elas podem ir se aproximando da inesgotável riqueza do Mistério". ${ }^{2}$ Compreendemos que o diálogo acontece na medida em que essa abertura está presente e entende que o Mistério é o único ponto verdadeiro que descentraliza e, na justa medida em que o acolhem, as confissões religiosas unem-se sem

1 TORRES QUEIRUGA, A. Autocompreensão cristã: diálogo das religiões. São Paulo: Paulinas, 2007, p. 8.

${ }^{2}$ Ibid., p. 8. 
imporem e aproximam-se sem se desrespeitarem, conservando cada uma a sua identidade, predisposta e receptiva, sempre em clima de reforma. O caminho do presente texto consiste em trabalhar quatro momentos: 1) a apresentação do problema; 2) a "particularidade" como uma necessidade histórica; 3) a unicidade ou plenitude da revelação divina; 4) o encontro das religiões.

\section{A apresentação do problema}

Já neste início é importante observar que, ao trabalhar este tema, a intenção é, na verdade, tratar a nova ideia de revelação trazida por Torres Queiruga. Em contrapartida à ideia de revelação divina compreendida de maneira fundamentalista, como uma espécie de "ditado divino", surge uma nova ideia de revelação, "como um 'dar-se conta' daquilo que Deus, desde sempre e sem discriminação, está tentando comunicar a todo o indivíduo, a toda comunidade e a toda cultura" ". Unida a essa nova ideia de revelação ou graças a ela surge a necessária compreensão de particularidade com destinação universal, porém situada e, por isso, desigual em suas configurações e conquistas. Isso só fica claro com a evolução do pensamento teológico e, consequentemente, da concepção de revelação. Torres Queiruga traz em sua literatura dois fragmentos citados respectivamente do Concílio de Florença do ano 1442 e Vaticano II de 1965, dos quais é essencial tomarmos conhecimento para entendermos como a compreensão humana acerca da revelação divina evolui com o passar do tempo. Vejamos:

Crê firmemente, confessa e prega [o concílio] que nenhum dos que existem fora da igreja católica, não somente os pagãos, mas também os judeus ou heréticos assim como os carismáticos, podem chegar a ser partícipes da vida eterna; pelo contrário, irão ao fogo eterno, "que está preparado para o diabo e seus anjos", a não ser que antes do fim da vida sejam agregados a ela [à igreja]. ${ }^{4}$

$[\ldots]$

A igreja católica nada rejeita do que nestas religiões [não cristãs] há de verdadeiro e santo. Considera com sincero respeito os modos de agir e viver, os preceitos e doutrinas que, embora discordem em muitos pontos do que ela professa e ensina, não poucas vezes, refletem um brilho daquela

\footnotetext{
${ }^{3}$ Ibid., p. 189.

${ }^{4}$ DS 1351; cf. também bula Unam Santam, 1302: DS 870 - Ver TORRES QUEIRUGA, A. $O$ Diálogo das religiões. São Paulo: Paulus, 1997, p. 5.
} 
Verdade que ilumina todos os homens. [...]. Por conseguinte, exorta a seus filhos que, com prudência e caridade, mediante o diálogo e a colaboração com os adeptos de outras religiões, dando testemunho da fé e da vida cristã, reconheçam, guardem e promovam aqueles bens espirituais e morais, assim como os valores socioculturais, que neles existem. ${ }^{5}$

Reflete Torres Queiruga - e percebemos com ele - que pode parecer impossível terem vindo estes textos da mesma instituição. Cronologicamente eles se distanciam 500 anos aproximadamente; ideologicamente poderiam parecer milênios. E o segundo, após passar 50 anos, tornou-se estranhamente tímido e restritivo. A tensão cronológica presente nos dois textos evidencia esse distanciamento entre a religião cristã e demais religiões. "Durante séculos, a teologia cristã pôde passar ao lado das religiões não cristãs sem notar a monstruosidade que supunha excluir seus fiéis da revelação e salvação

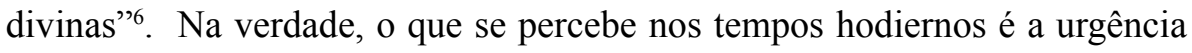
de proporcionar o encontro efetivo das religiões num mundo que se unifica aceleradamente. Cabe aqui enaltecer a sua importância para a construção da humanidade. Para essa empreitada é preciso estar muito atento à atual insuficiência da linguagem para expressar a nova compreensão da revelação do Mistério, sendo necessário ter consciência dos limites da autocompreensão a fim de ir elaborando conjuntamente uma compreensão mais universal. Daí a sugestão de Torres Queiruga em substituir a palavra "diálogo" por "encontro". Vejamos:

Talvez por isso convenha inclusive ir substituindo - ou pelo menos completando - a própria palavra "diálogo" pela palavra "encontro" [...]. O diálogo pode implicar conotação de uma verdade que já se possui plenamente e que vai ser "negociada" com o outro, que também já tem a sua. $\mathrm{O}$ encontro, pelo contrário, sugere muito mais um sair de si, unindo-se ao outro para ir em busca daquilo que está diante de todos ${ }^{7}$.

De qualquer forma, a novidade entre a perenidade do problema e de seu redelineamento não é algo secundário. A abordagem que aqui procuramos apoia-se num enfrentamento prévio do significado vital da religião e da

${ }^{5}$ COMPÊNDIO DO VATICANO II. Declaração "Nostra Aetate". Sobre as relações da Igreja com as religiões não cristãs. Petrópolis: Vozes, 1997, n. 2.

${ }^{6}$ Ibid., p. 9.

${ }^{7}$ TORRES QUEIRUGA, A. Autocompreensão cristã, p. 153. 
compreensão global da revelação e isso exige a renovação nos moldes globais de forma que possa fazer frente ao estado atual. Ao propor a compreensão global da revelação já se reivindica uma abertura para levar em conta de forma respeitosa todas as compreensões culturais globais.

Para isso, faz-se necessário partir do que Torres Queiruga chama de estrutura maiêutica da revelação. Essa consiste em "uma resposta real e concreta a perguntas humanas que são nossas perguntas; descobrimo-la porque alguém no-la anuncia, porém a aceitamos porque, despertados por esse anúncio, 'vemos' por nós mesmos que essa é a resposta certa" ${ }^{\text {" }}$. Nessa dinâmica, o profeta ou fundador religioso, ao invés de introduzir em seus fiéis algo externo a eles, ajuda-os a darem-se conta, a "darem à luz" o que já se encontra no seu íntimo a partir da realidade divina presente na história. É um ajudar a perceber que se Deus já estava presente desde sempre na história, Ele está fazendo o maior esforço para manifestar-se a todos na máxima medida. Pondera Torres Queiruga a esse respeito: "O limite não provém da 'mesquinharia' divina, que podendo revelar mais, não quer fazê-lo. Provém da inevitável limitação humana, infinitamente desproporcional ao mistério, que em generosidade irrestrita procura dar-se-lhe e manifestar-se-lhe por todos os meios" - reflexão esta que propõe uma compreensão de que Deus cria por amor a todos os homens e quer oferecer-se a todos como dom, sem, contudo, impedir a liberdade humana e o trabalho da história, essenciais à existência humana.

Num breve aceno podemos imaginar que, para a maioria dos teólogos, até boa parte do século XX, a idade estimada da humanidade era de uns seis mil anos, um mundo perfeitamente abarcável e dominável pela presença bíblica. Hoje, com a consciência da ampliação temporal e espacial, a Paleontologia fala de ao menos um milhão de anos para a vida da humanidade no planeta. São Paulo abrigou a ilusão de que o Evangelho alcançasse a todos os homens. Hoje, a partir da época dos descobrimentos, a ecumene clássica aparece como uma pequena mancha na imensidão dos continentes habitados. Acrescese a isso a explosão demográfica da humanidade. O que significa, então, a revelação bíblica? Qual pode ser a sua relação com as demais religiões da humanidade? Realça Torres Queiruga ao citar J. O. Percy que ninguém pode ler sem assombro declarações como a que, ainda em 1960, fazia o Congresso

\footnotetext{
${ }^{8}$ TORRES QUEIRUGA, A.O Diálogo das religiões, p. 12.

${ }^{9}$ Ibid., p. 12.
} 
sobre Missão Mundial em Chicago: "Nos anos a partir da guerra, mais de mil milhões de almas passaram à eternidade, e mais da metade delas foram ao tormento do fogo do inferno, sem sequer ter ouvido falar de Jesus Cristo: quem foi e por que morreu na Cruz do Calvário"10. Entendemos que o espanto não basta; é necessário ir além, remodelando o próprio conceito de revelação e abandonando esta concepção exclusivista.

Esse ir além será possível na medida em que houver um melhor conhecimento das demais religiões. Considera Torres Queiruga ao citar John Hick que "as religiões, são, cada uma delas, totalidades complexas de resposta ao divino..." ${ }^{11}$. E estas totalidades diferentes trazem diversas respostas humanas a partir do contexto das várias culturas. Criativamente Torres Queiruga traz o pensamento de P. Schimidt-Leukel: "também a teologia das religiões está sob o mandamento de não pronunciar nenhum falso testemunho contra $o$ próximo"12.

À luz das mudanças profundas da sociedade hodierna, compreende-se que é imprescindível a Teologia buscar novos enfoques e novas saídas para o problema do encontro entre as religiões. Conforme Torres Queiruga ${ }^{13}$, no mundo anglo-saxônico, impõe-se uma divisão tripartida das posturas, a saber: exclusivismo, inclusivismo ou pluralismo. O exclusivismo, como o próprio nome relembra, é a postura que só admite revelação real e verdadeira - e, por conseguinte, salvação - na própria igreja ou religião; essa posição, rigidamente falando, ninguém mais a sustenta. $\mathrm{O}$ inclusivismo não exclui nem verdade nem salvação nas demais religiões, mas mantém ao mesmo tempo a centralidade definitividade e absoluto - da própria, que "incluiria" a verdade das demais; incapacitação tanto para o diálogo como para o conhecimento das religiões constitui sua grande dificuldade. Daí nasceu a terceira postura - o pluralismo:

Para ele, todas as religiões são iguais, manifestações equivalentes em seu valor salvífico e em sua verdade, pois a diversidade nasce unicamente dos diferentes contextos culturais em que se tematiza e se concretiza a experiência do divino. [...]. Exerce hoje uma indubitável atração, que chega quase ao fascínio, talvez devido em parte a que se trata de uma reação generosa diante do fechamento histórico do exclusivismo, muitas

\footnotetext{
${ }^{10}$ Ibid., p. 15.

${ }^{11}$ Ibid., p. 16.

${ }^{12}$ Ibid., p. 17.

${ }^{13}$ Ibid., p. 18.
} 
vezes com trágicas consequências. Seu grande problema funda-se na questão da verdade, pois muito dificilmente pode evitar o perigo de um relativismo total, que não beneficiaria a ninguém ${ }^{14}$.

Assevera Torres Queiruga que, a partir da autocompreensão cristã, situamo-nos decididamente na órbita do inclusivismo, "não por um afã formalista de mediação abstrata, e sim porque o inclusivismo parece responder muito bem, ou ao menos suficientemente bem, às preocupações legítimas do respeito e da abertura aos demais, sem para tanto ceder à vertigem do relativismo" "15. Essa opção consiste apenas em um emolduramento formal, não como determinante do processo reflexivo que prejudicaria a gratuidade da experiência reveladora. Sendo assim, procuraremos que o problema do encontro surja a partir do processo vivo de uma reflexão que, ao buscar a si mesma, encontra-se em outros processos que a obrigam a voltar-se sobre sua postura, reconsiderando-a sob essa nova luz. "O Deus que aqui se revela a nós não aparece jamais como possessão própria nem salvação exclusiva, e sim como aquele que mantém sua transcendência gratuita e intrinsecamente destinada a todos"16. Sabemos que a grande tentação do afã possessivo humano tende a açambarcá-lo - basta lembrar-se da áspera história da intolerância. Mas é importante ressaltar: atualmente, a experiência cristã que anuncia a centralidade da revelação em Cristo - a ponto de anunciar que "não há salvação em nenhum outro" (At 4,12) - proclama igualmente a universalidade da salvação - que brota da mais íntima essência de seu Deus que é "amor" (Jo 4, 8.16) e que por isso mesmo "quer que todos os homens se salvem" (1 Tm 2,4). Há uma necessidade imposta à própria fé de efetivar a sua autocompreensão. O encontro das religiões se insere nessa dinâmica interna numa compreensão de dom e gratuidade contra todo domínio e concorrência.

O absoluto corresponde somente a Deus; o que cabe ao homem é a tarefa inacabável de ir assimilando-o, tanto na glória e na humildade do serviço, oferecendo aos demais o que descobriu, como na dura e prazerosa aprendizagem do que os outros lhe oferecem e que ele reconhece como pertencente a seu mesmo Deus, que é o de todos ${ }^{17}$.

\footnotetext{
${ }^{14}$ Ibid., p. 20.

${ }^{15}$ Ibid., p. 20.

${ }^{16}$ Ibid., p. 20.

${ }^{17}$ Ibid., p. 22.
} 
Aqui compreendemos que o encontro está sustentado nas exigências da sensibilidade moderna, brotando da própria experiência reveladora que não admite qualquer tipo de fechamento, preconceito ou afã de domínio. Sabemos que a hermenêutica atual convida a que estejamos abertos a qualquer confrontação dos nossos pressupostos da autocompreensão da revelação cristã. Isso posto, entendemos que toda mudança histórica, se por um lado faz surgir uma dificuldade, por outro oferece uma nova possibilidade de solução. E é a partir daí que vimos a particularidade como uma necessidade histórica.

\section{A "particularidade" como uma necessidade histórica}

A sensibilidade atual é alérgica a todo tipo de particularidade que venha a lesar a igualdade, a liberdade e a tolerância. O agudo sentido histórico que caracterizaessasensibilidadeafazcompreenderquetudo estáirremediavelmente situado no tempo e no espaço. Não é possível uma universalidade abstrata; só é possível a que circula lentamente e pelos caminhos da história. Avalia Torres Queiruga que a universalidade racional do Iluminismo - que quis realizar os ideais do universal humano sem a paciência dos condicionamentos concretos - foi paga com o terror da Revolução Francesa. Por isso, a teologia atual bem compreendeu que a verdadeira universalidade somente poderá realizar-se pela mediação histórico-particular. E por mais paradoxal que possa parecer, num mundo cada vez mais global, a consciência histórica nos faz ver que uma religião só poderá ser realmente universal partindo do interior de sua particularidade histórica que é potencialmente universal e que não pode ser aceita pela imposição da força, mas pela validez humana da oferta ${ }^{18}$.

O problema não reside no fato de a revelação cristã se delimitar em uma situação histórica; a questão radica-se em sua pretensão de universalidade, pois tal pretensão poderia implicar na exclusão das demais. Se fosse uma vontade de Deus, isso poderia soar como uma posição arbitrária de sua parte, mas se trata unicamente de algo inevitável numa história finita. Isso leva à pergunta: o que acontece com aqueles aos quais essa mediação histórica não chega? Se a revelação divina consiste na ação mais elevada e gloriosa que possa acontecer ao homem, já que é a comunicação salvadora do próprio Deus ao homem, não exigiria que, a partir de sua essência, sua presença fosse assegurada a todos? A partir do Iluminismo, tanto pela exegese crítica quanto pelo conhecimento mais profundo das religiões, sabemos que não existe

${ }^{18}$ Ibid., p. 26. Confira também TORRES QUEIRUGA, A. Autocompreensão cristã, p. 41. 
revelação isolada. Compreendemos que a revelação bíblica não constitui um "ditado divino" a seu povo. A comparação da tradição bíblica com as outras tradições religiosas mostra que nem aquela é tão "divina" que não permita ver o esforço, as falhas e feridas da reflexão humana, nem estas são tão "humanas" que não permitam apreciar a presença viva e salvífica do Divino. Se for assim, pode-se perguntar: onde fica a pretensão de universalidade? O que lança então as bases para entender que a revelação bíblica não tem por que significar o exclusivismo de um deus que, para cultivar um povo, abandona os demais.

Trata-se, isso sim, do Deus que, enquanto cultiva um, continua igualmente cultivando os outros. E o que possa haver de cultivo "especial" não é de modo algum um favoritismo excludente, e sim mais um meio do amor incondicional a todos; isto é, cada um, segundo as suas próprias circunstâncias. É uma estratégia do amor que faz com que por meio de um possa atingir a todos. E aquilo que poderia ser entendido como um favoritismo excludente passa a ser assimilado como o único modo possível de se realizar concretamente essa relação viva e real. Nesse sentido, faz-se necessário abandonar o termo eleição num sentido exclusivo, uma vez que todos são eleitos. Sabemos que todos são eleitos e chamados, mas a acolhida, por parte de cada um, é parcial e limitada. De sorte que essa acolhida tanto individual quanto por parte de uma religião particular deve estar aberta para ser completada pela contribuição do outro, bem como oferecer a sua própria contribuição.

Para não comprometer o sentido geral da revelação, como se Deus quisesse se revelar a uns e a outros não, compreende-se que:

Deus se revela sem reservas e a todos, com toda a força do seu amor, de sua sabedoria e de seu poder; os limites de sua revelação não são "queridos" por Ele, mas "impostos" pela insuperável finitude da captação humana. [...]. A culminação histórica do processo revelador, concebida como plenitude insuperável não poderia senão num ponto concreto. Tal ponto é o significado do mistério teândrico da pessoa de Cristo e sua necessária unicidade; por isso a sua captação já é, simultaneamente a confissão de sua fé. Mas essa plenitude está intrinsecamente destinada a todos; o Cristo, por essa razão não é "propriedade" dos cristãos, mas oferta a todos como possível culminação da fé que eles já têm a partir de sua própria história. Tal é o fundo de razão do "inclusivismo" e a base justa para o encontro "pluralista" das religiões, vista a partir do cristianismo ${ }^{19}$.

$\overline{19}$ TORRES QUEIRUGA, A. Autocompreensão cristã, p. 48. 
A partir da autocompreensão cristã, então, entendemos que o limite em perceber a revelação divina não pode ser evitado; ele provém da incapacidade da criatura para captar com mais clareza a sua revelação. Citando Santo Irineu, Torres Queiruga ressalta a pergunta que se fazia como objeção aos cristãos: "Onde estavam, nos séculos anteriores, os cuidados de uma tão grande providência?" e também que o Santo asseverava que se alguém pergunta se Deus não poderia fazer o homem perfeito desde o princípio, a resposta consiste em afirmar que Deus é todo-poderoso, mas que a criatura, pelo fato de ser criatura, é imperfeita e Deus a conduzirá por graus à perfeição como uma mãe que primeiro amamenta o seu filho e, à medida que cresce, vai lhe dando o alimento necessário. Torres Queiruga traz à tona também a citação de Henri de Lubacc de que "tudo é possível para Deus, mas a congênita debilidade da criatura impõe um limite à recepção de seus dons" ${ }^{20}$. É uma pena que essa intuição não tenha imbuído o discurso teológico sob o argumento, de corte voluntarista, de que Deus não se manifesta totalmente ao homem histórico porque "não quer", pois isso anular-lhe-ia a liberdade, mas o problema é que permanece o fantasma imaginativo de que, no fim das contas, as coisas são tão difíceis porque Deus assim o quer. É preferível acentuar a consequência: trata-se de uma impossibilidade estrita, tanto a partir de Deus (se pudesse ser captado por um ser histórico finito) - "se o compreendes, não é Deus" [S. Agostinho] - quanto a partir do homem que, pela sua essência finita, precisa realizar-se no trabalho e no amadurecimento do tempo. Em todo o caso é significativo para o nosso propósito o consenso de fundo: o reconhecimento da particularidade da revelação cristã como uma necessidade histórica.

\subsection{Não existe favoritismo divino}

Ao mesmo tempo em que há a imaginação de que Deus está real e salvificamente presente em todos os homens, existe o preconceito de que Ele somente se revelou na tradição bíblica. “A ‘eleição' de uns seria abandono dos demais; no melhor dos casos, à espera de que os eleitos vão mais tarde aos outros"21. O que compreendemos de forma contrária: Deus, impelido pelo seu amor livre e generoso, quer que todos sejam salvos e busca, por todos os meios, fazer-se sentir, o mais rápido e intensamente possível, por todos os

\footnotetext{
${ }^{20}$ Ibid., p. 52.

${ }^{21}$ TORRES QUEIRUGA, A. Diálogo das religiões, p. 37.
} 
homens e mulheres desde a criação do mundo. Não descuida de ninguém, nem há nele "acepção de pessoas" (Cf. Rm 2,11; Ef 6, 9; Cl 3, 25; 1 Pd 1, 17). "Ocorre que cada tradição o recebe à sua maneira e segundo a limitada medida de suas capacidades; mas de nenhuma ele se descuida, em todas está presente e de todas se serve para ajudar os outros"22. É como se Deus, no fundo luminoso do ser, estivesse pressionando continuamente a consciência da humanidade para emergir dela fazendo sentir sua presença (sua revelação). Onde se oferece um resquício, onde uma consciência cede livremente a sua pressão amorosa, ali ele concentra seu afã, aviva com cuidado o fogo que começa a nascer, continua apoiando-o com todos os meios de sua graça. E a partir desse ponto procura estender aos demais a nova descoberta, conciliando neles a pressão interna de sempre e o oferecimento externo que lhes chega da história. Aí a eleição, a partir desse contexto, estende-se a todas as religiões. Dessa forma ela significa o modo com que Deus se relaciona com uma tradição religiosa a partir não de uma eleição arbitrária, mas das condições reais que tornam possível esse relacionamento. A destinação divina é universal. Segundo Torres Queiruga, Deus se manifesta a todos como um professor que está tentando fazer com que uma classe compreenda uma teoria difícil. Ele se dirige a todos e por todos quer ser compreendido, mas quando, no seu empenho, percebe nos olhos de um aluno o brilho da compreensão, sem abandonar o ensino aos demais, procurará apoiá-lo e impulsioná-lo até o fundo do problema. Há liberdade por parte do professor ao decidir explicar. Pode haver a aparência de "eleição" no sentido de intensificar a relação professor-aluno, mas, se ele for um bom pedagogo, por meio desse aluno procurará com que a classe inteira chegue o mais rapidamente possível à idêntica compreensão.

\subsection{Existe, sim, a estratégia do amor universal}

A missão ou "eleição" particular da revelação bíblica de Israel, segundo Torres Queiruga, encaixa-se perfeitamente nessa forma:

Não se trata de que Deus "comece" sua manifestação com a história bíblica. O que ocorre é que, isso sim, no seio de sua manifestação à humanidade - e mais concretamente à específica humanidade que a partir da revolução neolítica vivencia essa manifestação nas religiões do Oriente Médio - um grupo determinado vai iniciar um tipo peculiar de experiência.

${ }^{22}$ TORRES QUEIRUGA, A. Autocompreensão cristã, p. 55. 
Uma peculiaridade que foi determinada por diversas circunstâncias, dentre as quais a experiência da saída do Egito, a localização num lugar de cruzamento de religiões e culturas, e sobretudo [...] o estilo ético, pessoal e histórico em que foi se configurando sua relação com Deus. [...], a autocompreensão cristã crê que, em conjunto, através desse grupo, foi aberto um tipo de experiência no qual - digamo-lo à nossa maneira - Deus encontrou, de fato, a possibilidade de ir potencializando um caminho rumo à manifestação alcançada em Cristo $^{23}$.

Aquilo que a tradição bíblica conquistou através de sua culminação em Cristo pode ser colocado agora à disposição de todos. Visto deste modo, a particularidade histórica, em princípio tão escandalosa, está longe de significar um favoritismo arbitrário, mas antes de tudo é uma autêntica estratégia do amor universal, para chegar, de forma única e plena, o quanto antes e do melhor modo, ao maior número possível de homens e mulheres.

\section{A unicidade ou plenitude da revelação divina}

A necessidade da particularidade histórica nos leva a entender essa plenitude e definitividade reconhecendo a verdade presente em todas as religiões. Está claro que a manifestação do Absoluto ocorre numa circunstância determinada de tempo e lugar, isto é, "sua manifestação nas diferentes culturas constitui uma evidência formal" ${ }^{24}$. A necessidade do diálogo nasce entre as religiões justamente diante da diversidade de ofertas. A partir da autocompreensão cristã, entende-se que em Cristo se alcançou uma plenitude única e definitiva. A livre decisão divina de comunicar-se plenamente encontrou em Jesus Cristo a máxima recepção possível na história. Isso não significa que essa culminação esteja em "poder dos cristãos" ou que eles a realizem com perfeição. Exatamente por ser culminação humana, constituindo um convite e desafio a entender que Ele é único e comum a todos, consiste em uma plenitude relativa e aberta.

Assim aconteceu com o próprio Jesus de Nazaré em quem, como humano, também a revelação foi fazendo nele o seu caminho e somente através da ruptura dos limites históricos pela morte pôde entrar na luz plena da ressurreição. Numa honesta e humilde abertura ao outro, na seara do

\footnotetext{
${ }^{23}$ Ibid., p. 58.

${ }^{24}$ Ibid., p. 71.
} 
diálogo ou do encontro, entendemos que não se abandona a própria oferta ou convicção, mas esta, por meio do diálogo, certamente tornar-se-á mais ampla, mais crítica e mais acolhedora. Essa dinâmica possibilita reconhecer o Ressuscitado na profunda dialética de pertença à história e à Igreja: não pertença, porque Ressuscitado vai para o Pai; pertença, porque apesar de tudo vai dando-se a conhecer em nossa história e mantendo-nos abertos à plenitude em que agora vive. Essa mesma lógica vale para a Igreja: pertença porque ela é a comunidade encarregada de manter viva a sua lembrança e efetivar a sua oferta; mas é também não pertença, porque, enquanto Ressuscitado, ela não o abarca, nem o possui e deve reconhecê-lo como destinado com igual direito a todos os demais. É preciso entender que a consciência da revelação tem de configurar-se continuamente ${ }^{25}$. No tempo presente, superada a compreensão da revelação como um "ditado", ela aponta para o caráter necessariamente interpretado. A essa tarefa de uma constante interpretação da revelação, Torres Queiruga propõe três categorias novas:

1) Universalismo assimétrico - Universalismo porque em seu nascimento e desenvolvimento histórico todas as religiões são, em si mesmas, caminhos reais de revelação e salvação. Isso porque expressa, da parte de Deus, sua presença universal e irrestrita, posto que desde a criação do mundo "quer que todos sejam salvos" (1 Tm 2, 4). Assimétrico, porque é impossível ignorar o fato das diferenças reais nas conquistas das diferentes religiões; não porque Deus discrimine, mas porque por parte do homem a desigualdade se torna inevitável ${ }^{26}$. Afirma Torres Queiruga que assimetria não é absolutismo, mas aponta para a compreensão de que todas as religiões, incluída a nossa, apresentam-se, em sua essência mais íntima, necessitadas de aperfeiçoamento e, como leques de tentativas exploratórias, partindo de instâncias distintas e por caminhos diversos, convergem para o Mistério que as sustenta, atrai e supera. São fragmentos diferentes nos quais se difrata sua riqueza inesgotável. Por serem fragmentos não devem ignorar-se, mas somar os reflexos. Seria monstruoso pensar que a riqueza do outro me empobrece e intolerável açambarcar como privilégio próprio o que pertence a todos. $\mathrm{O}$ caráter pleno deve abandonar toda pretensão de domínio ou conquista.

2) Teocentrismo jesuânico - Evidencia, por um lado, a imprescindibilidade

\footnotetext{
${ }^{25}$ TORRES QUEIRUGA, A. O Diálogo das religiões, p. 55.

${ }^{26}$ TORRES QUEIRUGA, A. Autocompreensão cristã, p. 96.
} 
de Jesus de Nazaré como pessoa histórica e, por outro, reconhece que, no fim das contas, o centro último é Deus. Daí a proposta dessa categoria como tentativa de juntar ambas as extremidades. "Hoje considero mais significativo falar de um 'teocentrismo jesuânico', pois me parece que aponta melhor tanto para Deus, enquanto Mistério ultimamente fundante, como para sua - para nós - irrenunciável mediação no Evangelho na pessoa de Jesus de Nazaré' ${ }^{27}$. Além disso, com relação aos demais, não prejulga em princípio seu direito de falar, se assim eles o creem, de um teocentrismo diferentemente qualificado.

3) Inreligionação - Podemos dizer que consiste na passagem da "religionação" à "inreligionação". Para melhor compreender, analogicamente: assim como na "inculturação" uma cultura assume riquezas que lhe vêm de fora, sem renunciar a ser o que ela é, o mesmo deve acontecer no plano religioso. Uma religião, que consiste em saber-se e experimentar-se como relação viva com Deus ou com o Divino, quando percebe algo que pode contemplar ou purificar essa relação, é normal que procure incorporá-lo. No contato entre as religiões, o movimento espontâneo, em relação aos elementos que chegam a uma religião proveniente de outra, deve ser o de incorporá-los ao seu próprio organismo, que dessa forma não desaparece; pelo contrário, longe de suprimir-se, afirma-se mediante uma transformação que pode torná-la mais crítica, mais rica e mais universal. É como no exemplo do enxerto de árvores em que tanto a árvore receptora quanto o galho enxertado se enriquecem mutuamente.

\section{O encontro das religiões}

Estudadas as questões já levantadas anteriormente, é possível pensar hoje o problema do encontro entre as religiões. Entende-se que esse encontro não só é possível, como é uma necessidade. Diante da compreensão de que todas as religiões são verdadeiras, parte-se de duas ideias: a) a presença real - salvadora e reveladora - de Deus no coração de toda a história dos homens, traduzida nas religiões - deve-se excluir o esquema cristianismo/religiões = revelação/não revelação; b) a necessidade histórica da "eleição" - aqui o esquema a eliminar é o de "nós sim"/“os outros não", traduzidos por "nós

${ }^{27}$ TORRES QUEIRUGA, A. Repensar a revelação: a revelação divina na realização humana. São Paulo: Paulinas, 2010, p. 366. 
verdadeiros"/“os outros falsos". A única dialética autêntica é a do "mais e menos" ou do "bom e melhor". Se partirmos do pressuposto de que todas as religiões, como tematização da constitutiva relação salvífica do homem com Deus, são verdadeiras, o diálogo brota por si mesmo. Isso faz com que cada religião busque internamente o melhor; assim, desaparece o espírito de competitividade para exercitar-se somente o de acolhida e oferecimento.

A perspectiva do diálogo sincero faz com que todos aprendam. Isso se expressa na certeza que torna o cristão bem sensível às deformações que encontra: o rosto entrevisto a partir da insuperável irradiação da vida de Jesus Cristo suscita o desejo irreprimível de fazê-lo brilhar também nos demais, eliminando sombras, corrigindo traços e abrindo as últimas profundidades. Mas, igualmente, está consciente das próprias deficiências: um encontro com a manifestação de Deus nas outras religiões constitui um convite a corrigir defeitos e, também, a descobrir novas riquezas em Deus que a inevitável estreiteza da própria tradição não lhe permitia ver. O que está em jogo aqui não é $o$ em si absoluto da comunicação de Deus, e sim o precário e relativo para nós da recepção. E, dado que esta se realiza como encarnação na polifonia do mundo, seria pretensão ingênua, para não dizer soberba blasfêmia, pensar que está plenamente realizada no cristianismo: há aspectos que, somente a partir de fora de sua configuração concreta, podem lhe chegar e que, justamente por fidelidade ao Deus seu e de todos, deve estar disposto a acolher.

\section{Considerações finais}

Por fim, faz-se necessário admitir que atualmente há uma insuficiência de linguagem. A partir da autocompreensão cristã como enraizamento hermenêutico do encontro, entendemos que quando se busca com humildade e acolhida o contato com o diferente, na disponibilidade de partilhar muitas verdades que são comuns a todos, efetiva-se a mútua ajuda, em que as outras religiões têm aspectos e perspectivas que nós não temos, auxiliando-nos a evidenciar e completar a nossa compreensão. Uma fé assim assumida se amplia ou aprofunda a si mesma com elementos ou perspectivas de outra. Diante de Deus sempre maior, é preciso manter a sensação viva do Mistério e a não monopolização que se tornou tão comum na humanidade hodierna que, aceleradamente, torna-se planetária e, na atual cultura, está tão castigada pelos diversos etnocentrismos. Entendemos que dessa cultura multifacetada, quando humanizada, poderão sair potencialidades inéditas sobre a partilha 
comum da captação da revelação divina que toca a história por meio da mão humana.

\section{Referências bibliográficas}

COMPÊNDIO DO VATICANO II. Declaração "Nostra Aetate". Sobre as relações da Igreja com as religiões não cristãs. Petrópolis: Vozes, 1997.

MIRANDA, Mário de França. O Cristianismo em face das religiões. São Paulo: Loyola, 1998.

MIRANDA, Mário de França. "Verdade Cristã e pluralismo religioso". Atualidade Teológica 13 (2003), pp. 32-49.

TORRES QUEIRUGA, Andrés. Autocompreensão cristã: diálogo das religiões. Trad. José Afonso Beraldin da Silva. São Paulo: Paulinas, 2007. (Coleção Algo a Dizer).

TORRES QUEIRUGA, Andrés. O Diálogo das religiões. Trad. Paulo Bazaglia. São Paulo: Paulus, 1997. (Comunidade e Missão).

TORRES QUEIRUGA, Andrés. Repensar a revelação: a revelação divina na realização humana. Trad. Afonso Maria Ligório Soares. São Paulo: Paulinas, 2010. (Coleção Repensar).

José Aguiar Nobre

Doutorando em Teologia Pastoral pela Pontifícia Universidade

Católica do Rio de Janeiro

Rio de Janeiro / RJ -Brasil

E-mail: nobre.jose@gmail.com

Recebido em: 14/07/15

Aprovado em: 18/03/16 